\title{
CLINICAL OUTCOME AND SURVIVAL OF LINK RS TOTAL HIP PROSTHESIS
}

SIRPA SAVILAHTI, IRINA MYLLYNEVA, T. SAM LINDHOLM, K. JORMA J. PAJAMÄKI, JUHA NEVALAINEN, PEKKA LAIPPALA

From the University of Tampere and the University Hospital, Tampere, Finland

We report the clinical outcome and survival of 100 total hip arthroplasties with Link RS cementless hip prostheses after a mean of 63 months (51 to 93). The average preoperative Merle d'Aubigné hip score was 9.4 points and the average score at the latest follow-up was 15.3 points.

Thirteen prostheses have been revised and seven await revision. Survivorship analysis based on intention to revise showed only $68 \%$ survival at seven years $(95 \%$ CI $53 \%$ to $81 \%$ ). The survivals of femoral and acetabular components verified to be loose at surgery were $78 \%$ and $89 \%$ respectively at seven years. A number of other patients have pain and it seems likely that there will be substantial reduction in these survival figures in the future.

J Bone Joint Surg [Br] 1995:77-B:369-73.

Received 4 May 1994; Accepted after revision 8 September 1994

S. Savilahti, MD, Research Assistant

I. Myllyneva. MD, Research Assistant

T. S. Lindholm. MD, Professor of Surgery

K. J. J. Pajamäki, MD, Associate Professor of Surgery, Clinical Lecturer J. Nevalainen, MD. Associate Professor of Surgery, Clinical Lecturer

Department of Clinical Medicine, University of Tampere, Teiskontie 35. 33520 Tampere, Finland.

P. Laippala, PhD, Associate Professor of Biometry

Department of Public Health, Biometry Unit. Medisiinarinkatu 3, 33520

Tampere, Finland.

Correspondence should be sent to Dr S. Savilahti.

(1)1995 British Editorial Society of Bone and Joint Surgery

0301-620X/95/3971 \$2.00
In addition to the clinical outcome after total hip arthroplasty (THR) using various scoring systems, survival analysis is a powerful tool particularly when failure rates are high (Dobbs 1980). It is better than simple reporting of percentage of failures at a given average follow-up, which tends to underestimate the true failure rate (Armitage 1971; Cornell and Ranawat 1986). Survivorship analysis can predict the success of arthroplasty by a statistically realistic method.

We report the clinical results and survivorship analysis of a series of patients followed for a mean of 63 months after primary hip arthroplasty using a smooth, uncemented hip prosthesis, the Link RS pattern.

\section{PATIENTS AND METHODS}

From January 1986 to October 1988, a total of 100 hips in 100 patients had primary THRs using the cementless Link RS femoral and acetabular components. Two other patients had a different acetabular component and were excluded from the study. The mean duration of follow-up for patients who had not had a revision was 63 months (51 to 93).

Seven patients had died during follow-up for reasons unrelated to the operation, but their follow-up data before death were included. Two patients were lost to follow-up, one at 1.5 years and the other at 3.5 years. The right hip was replaced in 59 patients and the left in 41 . For patients with bilateral Link THRs only the result from the first hip was used. There were 51 men and 49 women, and their age, weight, gender and diagnosis are recorded in Table I while Figure 1 shows their age distribution at the time of the operation.

For our first analysis, failure was defined as revision of one or both components. The indication for revision was intolerable symptoms due to clinical and radiological loosening. For our secondary analysis (Carr et al 1993) we used the decision to make a revision as the endpoint for failure, in order to include patients awaiting revision.

Clinical ratings were recorded by the method of Merle d'Aubigné and Postel (1954) as modified by Charnley (1979), preoperatively, postoperatively at one year and at the latest follow-up. An excellent result scored 16 to 18 points, a good result 14 to 15 points, a fair result 11 to 13 , and a poor result ten points or less. We attempted to 
Table I. Details of 100 patients with THR using the Link prosthesis with and without loosening

\begin{tabular}{llll}
\hline & $\begin{array}{l}\text { Loosening } \\
(\mathbf{n}=\mathbf{2 0})\end{array}$ & $\begin{array}{l}\text { Without loosening } \\
(\mathbf{n = 8 0})\end{array}$ & p value \\
\hline Age $(\mathrm{yr})$ & $56.2(38$ to 73$)$ & $57.6(26$ to 81$)$ & $0.59^{*}$ \\
Weight $(\mathrm{kg})$ & $73.9(49$ to 100$)$ & $77.2(45$ to 116$)$ & $0.94^{*}$ \\
Male:female & $9: 11$ & $42: 38$ & $0.55 \dagger$ \\
Diagnosis & & 59 & $0.45 \%$ \\
$\quad$ Primary osteoarthritis & 12 & 9 & \\
$\quad$ Rheumatoid arthritis & 4 & 12 & \\
$\quad$ Other diagnosis & 4 & & \\
\hline
\end{tabular}

* Student's $t$-test

†chi-squared test

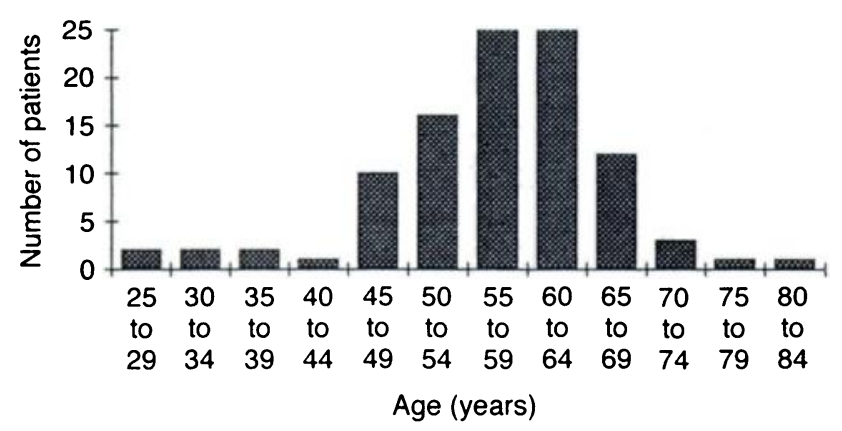

Fig. 1

Age distribution at the time of operation.

correlate these hip ratings with a number of factors such as unilateral or bilateral involvement, gender (Student's $t$-test), Charnley class, underlying disease (analysis of variance), age, body mass index (BMI, weight divided by squared height in metres) and weight (regression analysis).

We used the Link Rippen System cementless prosthesis (Fig. 2; Waldemar Link GMBH \& Co, Hamburg, Germany). The femoral stem is of Ti-6Al-4V with a head segment of a Co-Cro-Mo alloy. The stem is anatomically curved and its surface is deeply grooved. A proximal toothed configuration gives 80 horizontal load-transfer areas. The collar piece is removable. The component is available in $1 \mathrm{~mm}$ incremental sizes ranging from 8 to $16 \mathrm{~mm}$. The angle between stem and neck is $142.5^{\circ}$. The Ktype screw-in acetabular cup has a hemispherical shell and permanently fixed polyethylene inserts. The acetabular component, made of Ti-6Al-4V is available with outer diameters of 48 to $68 \mathrm{~mm}$.

Operations were by a posterolateral approach. The acetabulum was prepared by reamers of increasing size to expose subcortical cancellous bone. According to the manufacturer's recommendation, the screw-in cup was $4 \mathrm{~mm}$ larger than the last acetabular reamer. Care was taken to achieve bone contact at the dome of the cup.

The medullary canal and the neck of the femur were reamed and broached to attain optimal filling of the proximal medullary canal and perfect seating of the collar as recommended in the manual for the surgical procedure.

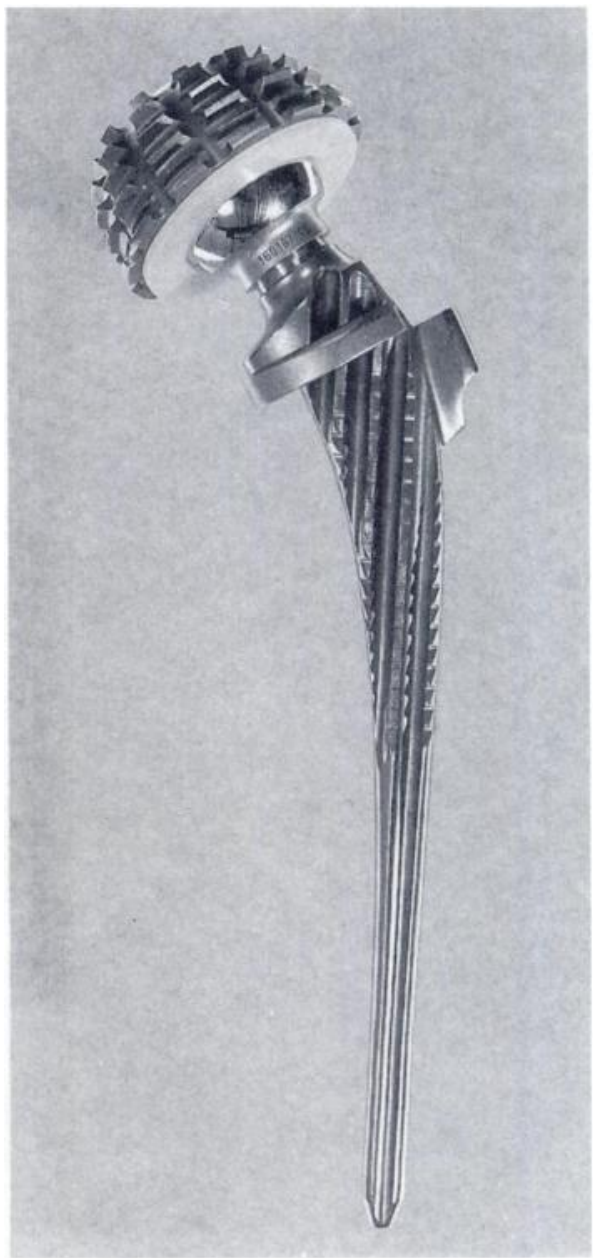

Fig. 2

Link RS total hip prosthesis: femoral and acetabular components.

When necessary, bone graft was placed between the ribs of the stem during insertion. The optional traction screw was placed through the lateral proximal spur of the stem into the greater trochanter when considered necessary. Only one patient had bilateral simultaneous replacements.

Partial weight-bearing was usually allowed on the first postoperative day with full weight-bearing normally after 


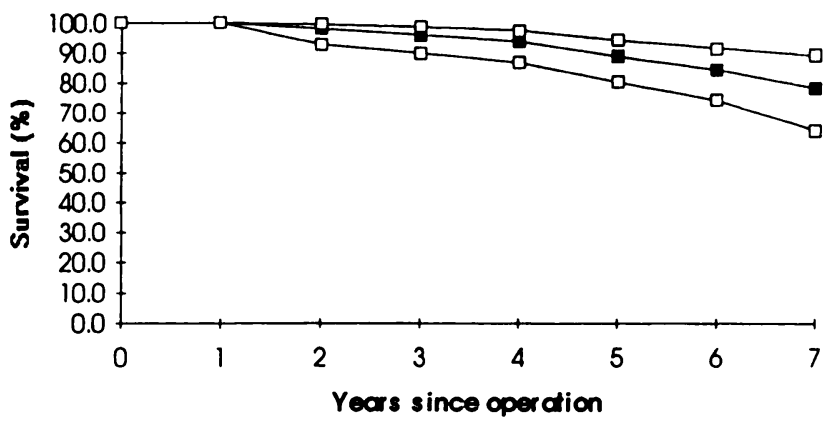

Fig. 3

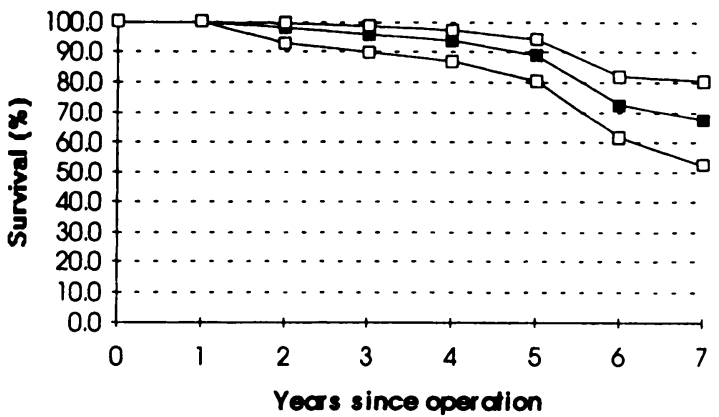

Fig. 4

Figure 3 - Survival curve for percentage of prostheses unrevised (black squares) with 95\% Cl (white squares). Figure 4 - Survival curves for the secondary analysis, taking the decision to make a revision as the endpoint for failure.

six weeks. Prophylactic cephalosporin was given immediately after the induction of anaesthesia and continued for two days. Anti-embolism stockings and early mobilisation were the most frequently used anti-embolic methods.

Statistics. We used the life-table method of calculation recommended by Murray, Carr and Bulstrode (1993) instead of the method described by Kaplan and Meier (1958) because the former includes details of the number of joints followed, the number of failures and the number lost to follow-up. The life-table method also allows confidence intervals to be more readily determined and displayed. Patients who were lost to follow-up at any given interval since operation were assigned the probability of failure for the interval in which they were lost. This approximation is valid if one assumes that the patients lost to follow-up experience the same rate of failure as those who remain in the study.

In patients having only femoral revision the acetabular components were retained in the survival study. When an otherwise acceptable acetabular component required revision to accommodate a stem revision the cases were withdrawn from the survival study.

\section{RESULTS}

The mean preoperative score for the modified Merle d'Aubigné rating scale was 9.4 points; postoperatively, at one year the score was 15.0 and at the latest follow-up of surviving hips was 15.3. At the latest follow-up the scores were excellent in 46 hips (59\%), good in 18 (23\%), fair in $13(17 \%)$ and poor in one $(1 \%)$. These clinical ratings did not correlate with the underlying disease, unilateral as against bilateral involvement, Charnley class, age, weight, BMI or gender.

The indications for the 13 revisions to date were late deep infection in two patients, a fracture of the femoral shaft in one, recurrent dislocation in one and aseptic loosening in nine patients. Another seven patients are awaiting revision and the data on these hips are also included in the study.
Survival figures with revision as the endpoint for failure are shown in Figure 3. A secondary survival analysis was made with the decision to revise as the endpoint for failure (Fig. 4, Table II). We made separate survival analyses for acetabular and femoral components (Figs 5 and 6) for which failure was defined as a loosened component verified by surgery. In the 13 patients with failure all the femoral components were loosened and eight of the acetabular components; in addition, two acetabular components were changed for technical reasons, and one of the non-revised acetabular components is awaiting revision.

\section{DISCUSSION}

The average modified Merle d'Aubigné hip score for this study was 15.0 at one year postoperatively and 15.3 at the latest follow-up. This compared favourably with the scores of 13.6 (at 30 months) and 16.6 (mean 34 months) reported by Jansson and Refior (1992) and Plotz et al (1992) respectively, but are not as good as those reported by Engh, Bobyn and Glassman (1987) (5.8 for pain and 5.6 for walking at five years).

Our results with the Link RS femoral component showed a survival of $89 \%$ at five years and $78 \%$ at seven years (95\% CI $64 \%$ to $89 \%$ ). This agrees with the only previously published report which we found for the Link RS prosthesis: Jensen, Christensen and Hørlyck (1994) reported femoral revision in $17 \%$ at a follow-up of 3 years ( 2 to $5)$. Our results were worse than those for porous-coated cementless implants. Success rates for the PCA prosthesis at five years with revision as the endpoint are reported to be well over $90 \%$ (Heekin et al 1993; Kim and Kim 1993). For the Harris-Galante femoral stem, Martell et al (1993) reported $97 \%$ survival at five years. Duparc and Massin (1992), however, using a smooth, cementless femoral component reported a survival rate of $77 \%$ at five years, less than that which we report.

The survival of the acetabular component in our series was $93 \%$ at five years and $89 \%$ at seven years $(95 \% \mathrm{CI}$ $76 \%$ to $96 \%)$. Jensen et al (1994) reported $11 \%$ revision of 


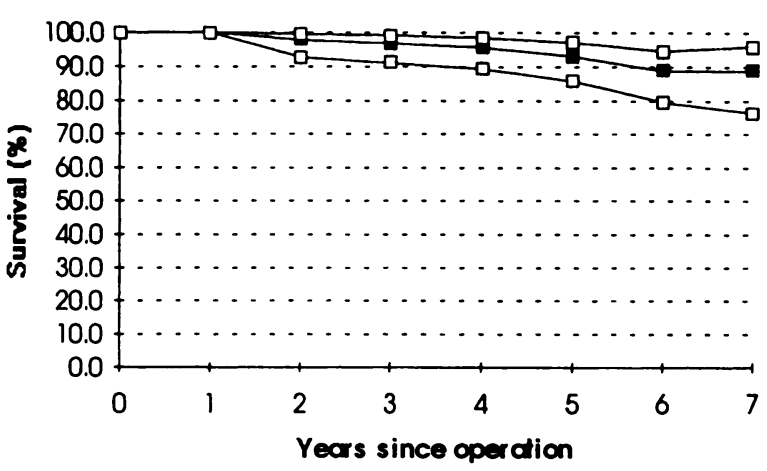

Fig. 5

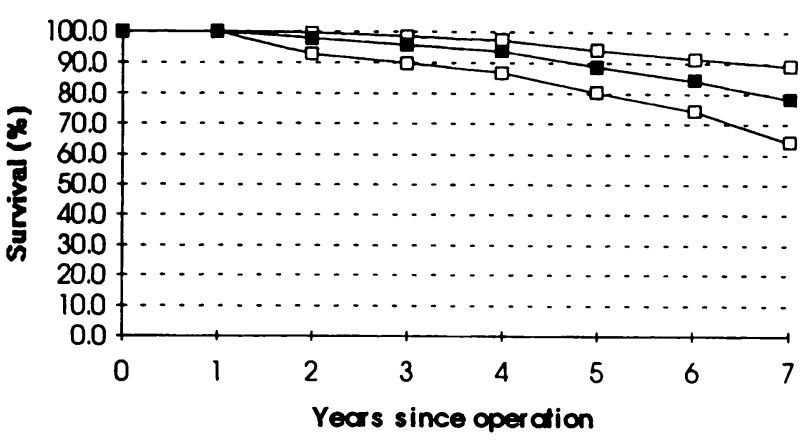

Fig. 6

Figure 5 - Survival curves for acetabular components. Figure 6 - Survival curve for femoral components.

Link RS acetabular components after a mean of three years. These results also are worse than those for porous-coated components (Engh, Griffin and Marx 1990). Schmalzried and Harris (1992) reported that none of their acetabular cups was revised because of loosening. The results for screw-in and smooth-threaded cups are generally poorer than those reported for porous-coated cups: Capello et al (1993) had a survival of $85 \%$ at four years; $21 \%$ of patients in the series of Engh et al (1990) had radiological signs of instability. Wilson-MacDonald, Morscher and Masar (1990) found a high rate of clinical loosening after eight years. A longer period of follow-up is probably needed to determine the true longevity of the Link RS acetabular cup.

In our secondary analysis of intention to revise, survival at seven years was only $68 \%$ (95\% CI $53 \%$ to $81 \%$ ). This poor survival rate is somewhat alarming, especially the rapid fall in the survival curve after five years. Lettin, Ware and Morris (1991) considered that survival analysis is of limited value unless there are at least 40 prostheses at risk for the duration of follow-up chosen for calculation, but Murray et al (1993) showed that if the last few years are not reported because of their unreliability, important information may be excluded.

The principle that cementless hip prostheses should be used for patients under 60 years of age has been widely accepted. In our series $42 \%$ of patients were over 60 years of age, but we found no correlation between loosening and age. We also failed to detect correlations with gender, weight or diagnosis, but our analysis does not exclude these factors since our numbers may be too low to demonstrate such correlations.

Our high incidence of loosening cannot be explained by the inexperience of surgeons. The average orthopaedic surgeon, such as did most of these operations, cannot match the results achieved by experts, but Malchau, Herberts and Ahnfelt (1993) have shown that the success rate of average surgeons using cementless THRs is well over $90 \%$. This implies that the loosening must be due to some other factor, such as operating technique or prosthesis design. We used the technique recommended by the manufacturer and conclude that this is not the reason for our high rate of loosening. The most probable reason appears to be the design of the prosthesis.

The smooth but ribbed and macrotextured surface of the stem is unique and is aimed to increase proximal support without stiffening the component. This design differs from that of conventional porous-coated stems which aim to attain cancellous fixation by micro-interlock. It became obvious in our cases that the grooved femoral surface did

Table II. Survival analysis with decision to revise as the endpoint for failure

\begin{tabular}{|c|c|c|c|c|c|c|c|c|c|c|}
\hline \multirow{2}{*}{$\begin{array}{l}\text { Years } \\
\text { since } \\
\text { operation }\end{array}$} & \multirow{2}{*}{$\begin{array}{l}\text { Number } \\
\text { at start }\end{array}$} & \multicolumn{4}{|c|}{ Withdrawn at latest review } & \multirow{2}{*}{$\begin{array}{l}\text { Number } \\
\text { at risk }\end{array}$} & \multirow{2}{*}{$\begin{array}{l}\text { Annual } \\
\text { failure rate } \\
\text { (per cent) }\end{array}$} & \multirow{2}{*}{$\begin{array}{l}\text { Annual } \\
\text { success rate } \\
\text { (per cent) }\end{array}$} & \multirow{2}{*}{$\begin{array}{l}\text { Cumulative } \\
\text { survival rate } \\
\text { (per cent) }\end{array}$} & \multirow{2}{*}{$\begin{array}{l}95 \% \text { confidence } \\
\text { interval }\end{array}$} \\
\hline & & Failure & Success & Lost & Died & & & & & \\
\hline 0 to 1 & 100 & 0 & 0 & 0 & 0 & 100.0 & 0.0 & 100.0 & 100.0 & 100.0 \\
\hline 1 to 2 & 100 & 2 & 0 & 1 & 3 & 98.0 & 2.0 & 98.0 & 98.0 & 92.8 to 99.6 \\
\hline 2 to 3 & 94 & 2 & 0 & 0 & 1 & 93.5 & 2.1 & 97.9 & 95.9 & 89.8 to 98.6 \\
\hline 3 to 4 & 91 & 2 & 0 & 1 & 2 & 89.5 & 2.2 & 97.8 & 9.3 .7 & 86.8 to 97.4 \\
\hline 4 to 5 & 86 & 4 & 23 & 0 & 0 & 74.5 & 5.4 & 94.6 & 88.7 & 80.3 to 94.1 \\
\hline 5 to 6 & 59 & 8 & 28 & 0 & 1 & 44.5 & 18.0 & 82.0 & 72.7 & 61.5 to 82.0 \\
\hline 6 to 7 & 22 & 1 & 16 & 0 & 0 & 14.0 & 7.1 & 92.9 & 67.5 & 52.5 to 80.5 \\
\hline 7 to 8 & 5 & 1 & 4 & 0 & 0 & 3.0 & 33.3 & 66.7 & 45.0 & 21.5 to 74.8 \\
\hline
\end{tabular}


not provide permanent stability of the component. It is more difficult to achieve good proximal fit and fill for initial stability with an anatomically-shaped femoral component like the Link RS than with the three-point cortical fixation attainable with a long straight stem (Bourne et al 1994). The stem design also seemed to contribute to suboptimal distal filling of the medullary canal; this has been shown to be associated with distal stem toggle and proximal loosening (Noble et al 1989). Suboptimal canal filling is well known to correlate with poor clinical results (Engh et al 1987).

We also consider that another factor may be the short offset of the prosthesis and the large neck angle of $142.5^{\circ}$ which together produce an unfavourable valgus position. In addition, the femoral component tended to lengthen the limb and to place it in slight adduction and internal rotation. Overcorrection of limb length is a possible reason for aseptic loosening. More research is needed to confirm the significance of these factors in explaining the high loosening rate which we report.

\section{APPENDIX}

Method of survival study. For each year of follow-up, the failure rate was calculated from the number of failures and the number at risk, determining the cumulative survival as the product of the probabilities for all intervals to that point. The analysis assumes that those withdrawn function for onehalf of the year for the interval in which they are lost. The number at risk therefore is the number at the start of the interval minus one-half the number of those withdrawn.

Cases were withdrawn from the study for the following reasons: death while the total hip replacement was still functioning; extension of the length of the study beyond the time for which the hip replacement had been functioning; or loss to follow-up.

We included $95 \%$ confidence limits as an indication of the reliability of the survival curves (Lettin et al 1991; Nelissen, Brand and Rozing 1992). We obtained confidence limits using Rothman's equation (1978) and the effective number at risk by the method recommended by Murray et al (1993). The 'effective number at risk' is the reciprocal of the average of the reciprocal of the numbers at risk in the year in question and each preceding year (the harmonic mean). This method takes into account the year in question but also includes information from the earlier years.

No benefits in any form have been received or will be received from a commercial party related directly or indirectly to the subject of this article.

\section{REFERENCES}

Armitage P. Statistical methods in medical research. Oxford, etc: Blackwell Scientific, 1971.

Bourne RB, Rorabeck CH, Burkart BC, Kirk PG. Ingrowth surfaces: plasma spray coating to titanium alloy hip replacements. Clin Orthop 1994:298:37-46.

Capello WN, Colyer RA, Kernek CB, Carnahan JV, Hess JJ. Failure of the Mecron screw-in ring. J Bone Joint Surg $[B r]$ 1993;75-B: 835-6.
Carr AJ, Morris RW, Murray DW, Pynsent PB. Survival analysis in joint replacement surgery. J Bone Joint Surg [Br] 1993;75-B:178-82.

Charnley J. Low friction arthroplasty of the hip: theory and practice. Berlin, etc: Springer-Verlag, 1979:20-5.

Cornell CN, Ranawat CS. Survivorship analysis of total hip replacements: results in a series of active patients who were less than fiftyfive years old. J Bone Joint Surg [Am] 1986;68-A:1430-4.

Dobbs HS. Survivorship of total hip replacements. J Bone Joint Surg [Br] 1980;62-B:168-73.

Duparc J, Massin P. Results of 203 total hip replacements using a smooth, cementless femoral component. J Bone Joint Surg [Br] 1992;74-B:251-6.

Engh CA, Bobyn JD, Glassman AH. Porous-coated hip replacement: the factors governing bone ingrowth, stress shielding, and clinical results. J Bone Joint Surg [Br] 1987:69-B:45-55.

Engh CA, Griffin WL, Marx CL. Cementless acetabular components. J Bone Joint Surg [Br] 1990;72-B:53-9.

Heekin RD, Callaghan JJ, Hopkinson WJ, Savory CG, Xenos JS. The porous-coated anatomic total hip prosthesis, inserted without cement: results after five to seven years in a prospective study. $J$ Bone Joint Surg [Am] 1993;75-A:77-91.

Jansson V, Refior HJ. Clinical results and radiologic findings after cementless implantation of PCA stems in total hip replacement. Arch Orthop Trauma Surg 1992:111:305-8.

Jensen HP, Christensen KS, Hørlyck E. Cementless total hip replacement with the LINK Ribbed System. Acta Orthop Scand 1994;65(Suppl 256):7.

Kaplan EL, Meier P. Nonparametric estimation from incomplete observations. J Am Stat Assoc 1958;53:457-81.

Kim Y-H, Kim VEM. Uncemented porous-coated anatomic total hip replacement. J Bone Joint Surg [Br] 1993;75-B:6-13.

Lettin AWF, Ware HS, Morris RW. Survivorship analysis and confidence intervals: an assessment with reference to the Stanmore total knee replacement. J Bone Joint Surg [Br] 1991;73-B:729-31.

Malchau H, Herberts P, Ahnfelt L. Prognosis of total hip replacement in Sweden: follow-up of 92675 operations performed 1978-1990. Acta Orthop Scand 1993;64:497-506.

Martell JM, Pierson RH III, Jacobs JJ, et al. Primary total hip reconstruction with a titanium fiber-coated prosthesis inserted without cement. J Bone Joint Surg [Am] 1993:75-A:554-71.

Merle d'Aubigné R, Postel M. Functional results of hip arthroplasty with acrylic prosthesis. J Bone Joint Surg [Am] 1954;36-A:451-75.

Murray DW, Carr AJ, Bulstrode C. Survival analysis of joint replacements. J Bone Joint Surg [Br] 1993;75-B:697-704.

Nelissen RGHH, Brand R, Rozing PM. Survivorship analysis in total condylar knee arthroplasty: a statistical review. J Bone Joint Surg [Am] 1992;74-A:383-9.

Noble PC, Kamarlo E, Alexander JW, Mahoney OM, Tullos HS. What makes cementless implants work?. Proc 56th meeting AAOS 1989.

Plotz W, Gradinger R, Rechl H, et al. Cementless prosthesis of the hip joint with 'spongy metal' surface: a prospective study. Arch Orthop Trauma Surg 1992;111:102-9.

Rothman KJ. Estimation of confidence limits for the cumulative probability of survival in life table analysis. $J$ Chronic Dis 1978:31:557-60.

Schmalzried TP, Harris WH. The Harris-Galante porous-coated acetabular component with screw fixation. J Bone Joint Surg [Am] 1992;74-A:1130-9.

Wilson-MacDonald JW, Morscher E, Masar Z. Cementless uncoated polyethylene acetabular components in total hip replacement: review of five- to 10-year results. J Bone Joint Surg $[B r \mid$ 1990;72-B: 423-30. 